\title{
GCU
}

Glasgow Caledonian

University

University for the Common Good

\section{Enhancing employability skills through internships: perceptions of foreign Master students in Germany}

Kapanen, A.; Dressler, S.; Edgar, D.; Rachfall, T.

Published in:

ICERI2016 Proceedings

DOI:

10.21125/iceri.2016.1000

Publication date:

2016

Document Version

Author accepted manuscript

Link to publication in ResearchOnline

Citation for published version (Harvard):

Kapanen, A, Dressler, S, Edgar, D \& Rachfall, T 2016, Enhancing employability skills through internships: perceptions of foreign Master students in Germany. in ICERI2016 Proceedings. IATED, pp. 1-10, 9th annual International Conference of Education, Research and Innovation, 14/11/16.

https://doi.org/10.21125/iceri.2016.1000

\section{General rights}

Copyright and moral rights for the publications made accessible in the public portal are retained by the authors and/or other copyright owners and it is a condition of accessing publications that users recognise and abide by the legal requirements associated with these rights.

Take down policy

If you believe that this document breaches copyright please view our takedown policy at https://edshare.gcu.ac.uk/id/eprint/5179 for details of how to contact us. 


\title{
ENHANCING EMPLOYABILITY SKILLS THROUGH INTERNSHIPS: PERCEPTIONS OF FOREIGN MASTER STUDENTS IN GERMANY
}

\author{
A Kapanen ${ }^{1}$, S Dressler ${ }^{1}$, D Edgar ${ }^{2}$, T Rachfall ${ }^{1}$ \\ ${ }^{1}$ HTW Berlin (GERMANY) \\ ${ }^{2}$ Glasgow Caledonian University (UNITED KINGDOM)
}

\begin{abstract}
This paper investigates foreign postgraduate students' perceptions of learning and deploying employability skills through internships at German companies. It presents a mixed-method qualitative survey combining a student self-assessment questionnaire and in-depth interviews. A thematic analysis of data collected from nine participants results in the development of 18 themes related to learning and deploying employability skills. These themes provide a provisional resource for internship stakeholders - students, academic advisors and internship providers - for developing ways to enhance internship learning outcomes.
\end{abstract}

Keywords: Employability, higher education, internships, Germany, international education

\section{INTRODUCTION AND PURPOSE}

Internships, that is "a period of time during which someone works for a company or organization in order to get experience of a particular type of work" (Cambridge English Dictionary online: http://dictionary.cambridge.org/dictionary/english/internship) have a long history of use in higher education, acting as a useful bridge from studies to employment [1]. As a form of experiential learning, internships allow students to apply and contextualise what they have learned at the university and to develop tacit and generic employability skills that are difficult to teach in the classroom [2] [3]. They provide a host of other benefits including an improved student experience [4], improved graduate selfefficacy and career confidence [5], as well as an opportunity to connect with potential employers and demonstrate practical ability and synthesis [1]. Overall, there is broad agreement that internships, when appropriately designed for the needs of undergraduate or postgraduate students, have a positive impact on graduate employability [1] [3] [6].

While native postgraduate students possessing prior relevant working experience may perceive internships to have little impact on their future job prospects, foreign students aiming at postgraduation employment in their host countries may utilise internships to adapt to the local job market and work culture. However, Trompenaars and Hampden-Turner [8] (p. 6) argued, in their seminal book over two decades ago, that even proven work-related practices and behaviours tend to "lose effectiveness when cultural borders are crossed." Therefore, such cultural differences, especially when not made explicit and addressed, can diminish foreign graduates' employability in the job market. Internships are a potential instrument for mitigating this problem. They facilitate an experiential learning opportunity supported by the university and aligned to the overall learning experience. For employers, limited commitment, supportive legal conditions, the opportunity to connect with universities, gaining fresh ideas and the opportunity to assess students for later employment are among the incentives to offer internship placements [7].

This research focuses on German employers, as they have an increasing stake in improving foreign graduate employability and many German Universities have considerable numbers of foreign students. The number of students who completed their entrance qualification abroad reached 320,000 in 2015, representing about 12 percent of all students enrolled in Germany [9]. Of new enrolments, foreign students represent about 20 percent [9]. In 2015, a joint survey by the Stifterverband and McKinsey discovered that every second German company tended to rely on foreign graduates to meet their staffing needs and two-thirds believed that recruiting foreign graduates would become more important in the future [10]. Nevertheless, recent studies and surveys point out that while $75-80 \%$ of foreign students wish to stay in Germany to work after graduation, only $25 \%$ are able to enter full-time employment [11] [12]. This indicates a significant issue with foreign graduate employability, which is widely acknowledged but to date has only been superficially investigated. This is the focus of our paper. 
Placing this study in a context requires defining the concept of employability. A basic definition is supplied by Brown et al. (2003) [13] who view employability as "the relative chances of acquiring and maintaining different kinds of employment." Employability is, however, a complex, multifaceted, situational and lifelong concept that depends on a large number of individual factors, personal circumstances and contextual factors [14]. Fig. 1 presents a comprehensive, but by no means exhaustive, sample of the determinant factors of employability.

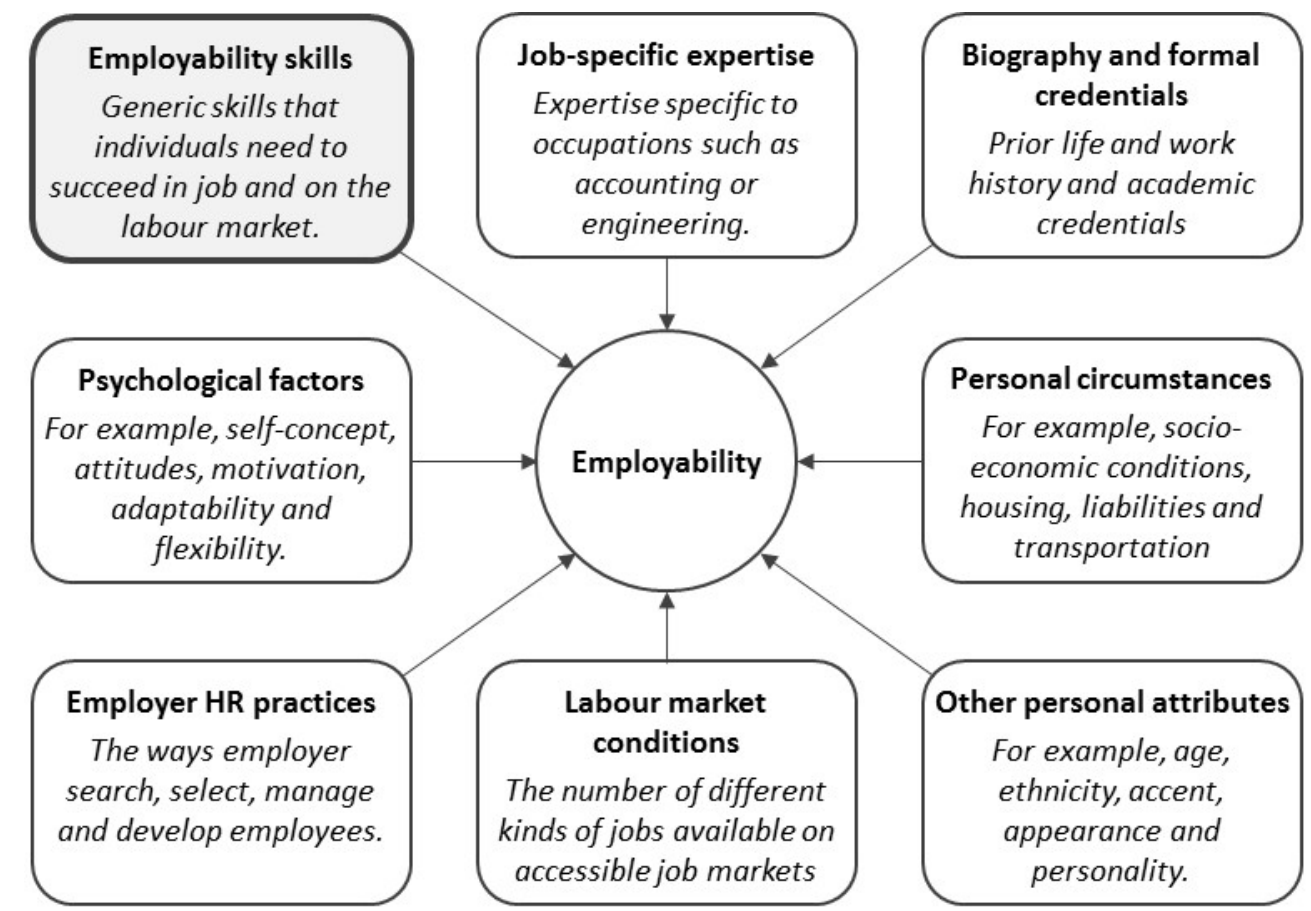

Fig. 1. Overview of the determinant factors of employability with the research area highlighted.

(Authors' illustration based on [14], [15], [16] and [17])

As depicted in Fig 1, the concept of employability is too complex to serve an instrumental or empirical purpose. In higher education debate, this problem is typically solved by focusing on how postgraduation career chances are influenced by those graduate competences and attributes that can be influenced through higher education pedagogy [17]. This narrow, individual-centred view is often referred to as graduate employability [17]. Although criticised as being insufficient to predict graduate employment outcomes, at institution level graduate employability can be a useful concept for assessing the practical relevance of education and improving the university-industry link [13] [18] [19].

An important determinant of graduate employability are employability skills [20]. ${ }^{1}$ Employability skills refer to skills that are necessary for individuals to obtain, keep and succeed in employment [20]. Literature and web resources provide extensive lists of specific skills but to summarise, employability skills allow individuals to organise and manage their effort; communicate and collaborate with others; identify, analyse and solve problems; and seek and process information to an adequate degree of effectiveness and efficiency [20]. Because employability skills link to the norms and expectations concerning behaviour, communication and social interaction and performance at work, they are at least partly embedded in the surrounding culture. Therefore, it is justified to propose that understanding difference between employability skills in different contexts and developing employability skills particularly useful in the German context can contribute to foreign students' and graduates' employability on the German job market.

The objective of the study is to investigate foreign postgraduate students' perceptions of learning and deploying employability skills through internships at German companies. The initial motivation to conduct the study was to improve student advisory and internship preparation in the degree

\footnotetext{
${ }^{1}$ Employability skills are typically used synonymously to generic skills, transferable skills or core skills.
} 


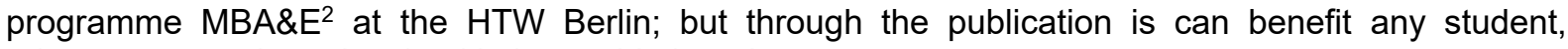
educator or employer involved in internship learning.

This section discussed the problem of foreign graduate employability from which this study emerges, defined the key concepts and formulated the research objective. The following section 2 describes the empirical methodology and the findings. Section 3 continues with a thematic analysis of the findings. Finally, section 4 reviews the research objective and concludes on the research.

\section{METHODOLOGY AND FINDINGS}

The study was designed and conducted in August and September 2016. The research process was broken down into four steps that included research design, data collection, data analysis and conclusions. Fig. 2 illustrates the research process. Steps 1 and 2, as well as the analysis procedure applied in step 3, are described in this section. The analysis results of step 3 , as well as step 4 , are presented in the following two sections, respectively.

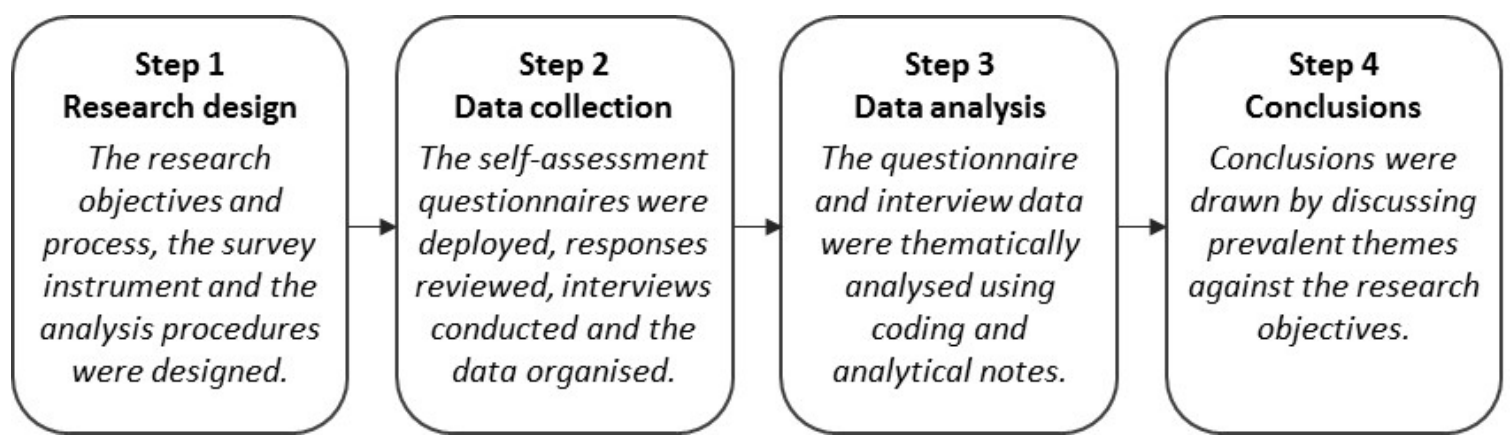

Fig. 2: Overview of the research process.

In step 1, the study was designed. The research objective emerged from education practice and was contextualised in the literature survey presented in section 1. The objective called for an in-depth exploration of the participant experiences of learning employability skills. Therefore, a mixed-method, qualitative methodology with an inductive orientation was chosen. A survey instrument consisting of two components was developed:

1. A self-assessment questionnaire covering eight employability skills areas

2. An interview guide, customised for each participant on basis of the self-assessment

The self-assessment questionnaire was compacted and modified from the "Portfolio of employability skills for young people", developed within the European OVPELO ${ }^{3}$ project. The purpose of the questionnaire was to initially chart individual learning experiences, as well as to motivate the participants to reflect on those experiences in preparation for the interview. On basis of the questionnaire responses, interview guides consisting of a general part and an individual part were developed. The questionnaire and the interview guides are too extensive to be reproduced here but are described briefly below.

The questionnaire covered eight employability skills areas that correspond to subsections $3.2-3.9$ of this paper. Each area was divided into 3-5 skill statements such as "I am able to successfully interact with others at work." The participants were asked to assess their proficiency in each skill both before and after the internship experience. In addition, they were asked to evaluate the importance of each skill to their internship success. A scale from 1 (beginner/unimportant) to 10 (expert/very important) was used for all ratings. In addition, free-text responses could be provided to elaborate on the ratings. The questionnaire was intended as a pre-stage of the study. The main data collection instrument, the in-depth interview, was designed to explore in further depth how the participants had manifested or

\footnotetext{
2 The Master of Business Administration \& Engineering (MBA\&E) is an international and interdisciplinary postgraduate programme taught in English at the HTW Berlin, University of Applied Sciences, in Germany. For further information, please see http://mbae.htw-berlin.de/.

${ }^{3}$ The project "Optimisation of validation process of EVS learning outcomes" (OVPELO) was completed between 2014 and 2016 by a multinational European consortium. The project, funded by the Erasmus+ programme, was established to enhance the recognition of learning achieved through international European Voluntary Service (EVS) internships. Further information is available at http://www.volunteersemployability.info/.
} 
learned employability skills, what impediments to learning they identified and what significance they attached to their experiences.

In step 2, the data was collected. As the amount of data per participants was significant, only a small sample could be handled. The main challenge was to acquire participants motivated enough to spend 2-3 hours on the self-assessment and another 30 minutes on the interview. An interview request was distributed on the mailing list of MBA\&E students and graduates, as well as on two social media groups for foreign students in Germany. The effort resulted in nine participants (designated in the order in which they offered participation):

- P1: Male MBA\&E student, 31, from Latin America, recent industrial marketing intern at an engineering multinational in Bavaria.

- P2: Male MBA\&E student, 29, from South Asia, current international sales intern at an automotive manufacturing multinational in Bavaria.

- P3: Male MBA\&E graduate, 27, from South Asia, recent project management intern at a transportation systems multinational in Berlin.

- P4: Female MBA\&E student, 27, from Latin America, current production intern at an automotive manufacturing multinational in Lower Saxony.

- P5: Female MBA\&E graduate, 27, from Latin America, recent human resources management intern at a professional services multinational in Berlin.

- P6: Male business informatics student, 28, from Southeast Asia, current information technology intern at a professional services multinational in Baden-Wuerttemberg.

- P7: Male MBA\&E student, 27, from South Asia, current intern at an engineering multinational in Baden-Wuerttemberg.

- P8: Male MBA\&E student, 27, from South Asia, current product management intern at an automotive manufacturing multinational in Hesse.

- P9: Female business administration student, 30, East Europe, recent intern at a project management SME in Saxony.

The interviews were conducted using Skype and recorded as MP3 audio files. The recordings were screened and stripped of extraneous segments, resulting in 172 minutes of audio data. The data was next cut into segments corresponding to subsections 3.1 - 3.9 of the paper. The data was then subjected to a thematic analysis simplified from the procedure proposed by Braun and Clarke [21]:

- Step 1: Familiarising yourself with the data. The interview transcripts were iteratively reviewed to understand their content.

- Step 2: Generating initial codes. Through continued review, interesting features among the data were identified and recorded as initial codes.

- Step 3: Searching for themes. The initial codes were analysed and combined to form coherent themes, highlighted throughout section 3 .

- Step 4: Refining and discussing themes. The themes were refined and the data was reviewed again to identify further instances and quotations that could explain each theme further.

This section presented the research methodology and described the findings. The results of the thematic qualitative data analysis are presented next, followed by conclusions in section 4 .

\section{ANALYSIS AND DISCUSSION}

The subheadings in this section correspond to the structure of the survey instrument. Subsection 3.1 discusses the participants' overall perceptions, explored through open interview questions. Subsections $3.2-3.9$ correspond to the eight employability skills areas of the survey instrument. The discussion is organised around themes developed during the analytical procedure; the themes are embedded in the text and marked in bold letters.

\subsection{General perceptions of internship learning}

All participants could describe with relative ease how they initially expected the internship to contribute to their future career chances. Among the diversity of responses, strategies to seek both short-term and long-term benefits could be identified. In addition to the expected learning, the interviews asked about significant unexpected learning experiences and outcomes. 
Students setting short-term strategies focused on gaining foothold on the German job market and becoming familiar with the German work culture. For P7, the internship was an opportunity to "test" the German job market and gain an "good overview of how it all works". P2 sought an insider perspective to key questions like how employers evaluate candidates, how jobs and organisations are designed and how foreign graduates fit in. P5 experienced the internship as an opportunity to demonstrate her potential for future employment. P2 saw the internship an opportunity to gain an insider reference to later employment. Overall, the participants perceived the task of gaining post-graduation employment challenging and actively sought to use their internships to bridge to post-graduation employment.

Nevertheless, the participants also demonstrated setting long-term strategies. P1 - the most experienced participant among the sample - sought an experience decisively different from his prior work experience in order to broaden his employability in long term. Also P3 saw the internship as a professional exploration opportunity, observing that he was rather driven by general curiosity than occupational learning goals. In contrast, a narrowing strategy was followed by P4, P7 and P8, who sought internships in specific areas in order to deepen professional specialisation. P4 believed to have gained her internship because of her pre-existing technical expertise and sought further occupational specialisation through it. P6 also brought up the point of integrating to the professional community as a form of long-term career development. P2 reported benefiting of the internship as a form of selfassessment, which helped him explore his own capabilities and preferences and improve his sense of "career realism", in particular in the German context. Similarly, P5 saw the internship as a means of identifying her competitive advantages on the job market. Evaluating potential companies to intern at, P3 chose one with strong presence in his home country in order to open job opportunities there in case he moved back. The number of long-term strategies indicates a forward-looking attitude among the participants.

All participants reported their internships to have mostly met their immediate expectations. In addition, six participants (P2, P3, P5, P6, P7 and P8) were able to describe unexpected learning outcomes. All five participants were surprised by the international dimension of their internships; communicating across cultures and continents using a variety of media belonged to their daily work, placing high demands on their communication skills. P3, P5 and P8 found they were given significantly more responsibility and workload than they expected, which they saw as an important driver of learning. P3 reported this pressure led him to "get immersed" in the workplace culture, leading to accelerated adaptation to the business environment and enhanced self-efficacy.

The general interview questions prompted the participants to set a context for the study, drawing on their own experiences and using their own terminology. The participants had achieved a number of expected and unexpected learning outcomes, some of which linked to employability skills. The next sections will analyse responses to the eight employability skills areas of the survey in further detail.

\subsection{Self-awareness, self-management and autonomy}

This was one of the areas most elaborated in the responses. Most participants reported an increase in the level of performance pressure compared to on-campus studies, which required them to reflect upon their work behaviour and resulted in learning in this area. The findings could be grouped under three main themes.

Learning through expanding limits describes the learning experience related to overcoming challenging periods during the internship. P8 reported having "no choice but to adapt" when struggling to complete the workload. Through such situations, P3, P5, P7 and P9 reported learning time management, focus, setting realistic objectives, anticipative behaviour and keeping buffers for the unexpected. P5 and P7 admitted being initially overconfident but learning from being brought to the limit of their capacity. As P7 reported improving his stress resistance by realising that "when you know your limits, you are able to say no and not make promises you cannot keep." According to P3, his organisation values employees who can "handle complex situations and work diligently under challenging situations" and resist stress.

An associated theme, prioritising and managing tasks, belongs to the competences required to meet targets and deadlines under challenging circumstances. Several participants found a culture of self-managed individuals taking responsibility for completing series of tasks and projects different from their native work cultures, which were more oriented toward multitasking $(P 1)$ and group work (P3, P6, P7) and more manager-led (P9). P3 saw balancing between daily tasks and allocated time for project work key to productivity. P5 observed that learning to manage her work in small SMART objectives helped her combat procrastination and effectively use times when waiting for input from others. P3 
and P9 emphasised the importance of learning to coordinate work well, providing others with timely and appropriate inputs to work on while autonomously moving on to the next priority task.

Several participants discussed a process of becoming autonomous. They understood autonomy not as working in isolation but rather the ability to complete work, learn and collaborate without task level supervision. P2, P6 and P7 reported having initially sought supervisor guidance and approval but learning to trust their ability to work autonomously partly through experience and encouragement, partly due to the unavailability of support. As P8 commented, "you have to be adaptable ... you have to go learn yourself and apply it because you have tons of responsibilities at the same time and everybody is the same, they will have very little time for you." Becoming autonomous, as well as prioritising and managing tasks, link to the intern's ability to work effectively in the surrounding organisational setting, which is discussed next.

\subsection{Organisational competence}

Integrating to the organisation was experienced by the participants as a source of diverse and significant learning experiences. The interaction with colleagues provided the participants an opportunity to learn about the work practices, systems, expertise, attitudes, values and styles present in the organisation. Three main themes could be identified among the survey data.

The first theme is sensing organisational priorities. P5 explained that especially early in the internship, it may not be clear to the intern how the organisation creates value to its customers and other stakeholders. P7 linked this theme to the process of becoming autonomous: after learning which priorities guide the organisation, he could more easily prioritise tasks and identify useful work to do. P3 provided a concrete example of linking organisational priorities to one's own work. Discovering how the department understood 'performance' by investigating its system of performance indicators, he aligned his behaviour to these measures and reported improving the relevance of his work. This example also illustrates the importance of initiative and curiosity in learning organisational competence.

Several participants perceived developing an inquisitive mindset as prerequisite to discovering the organisation. As P9 explained, "you can only make yourself useful when you know what's going on ... no-one will come to you to explain it, you just need the courage to go to people and talk ... your network is the key to most things you can do." P5 found the skill to ask questions a key workplace skill, which she developed during the internship. Doing so, she overcame a social barrier to communication: Initially she had avoided asking questions in order to maintain a "knowledgeable impression" among colleagues. P4 observed that often basic understanding of a topic is sufficient for posing good questions to subject matter experts. A good summary of the essence of the theme was provided by P3, who stated, "I am curious, I try to learn things, I try to get into the tasks. Maybe I'm not the expert in that but I jump into it ... if I don't know this answer, maybe a second person sitting in Americas knows it, or the third person on the third floor knows it. I tried to create this network, and what I found was that there are very good people, you just have to ask."

The last theme, getting to know the organisation, refers to the participants' ability to locate support and resources within the organisation. It emerges from both understanding of the formal organisation and personal connections. P2 and P8 reported that understanding which services and expert resources are available in the organisation belongs to critical workplace knowledge that they learned early in the internship. P1 and P8 remarked that it was important to recognise the social manner, medium and time of communication that were the most appropriate for making the social connection to gain support. P3 and P6 went a step further, pointing out that gaining colleagues' committed collaboration often requires an explicit mutual interest; "people need to know why they should invest their time in [working with you]" (P3).

\subsection{Problem-solving}

Problem-solving remained an area that gained relatively little attention in the interviews. The participants considered problem-solving skills important and could provide examples of problemsolving from their internship experience. However, only brief comments on learning explicit problemsolving skills were provided. The main theme of these comments was defining problems. P4 and P7 described working on complex, exploratory projects where problems were not obvious. Thus, their learning experiences involved analysing and defining problems so that tangible solutions to be found. P5 remarked that learning how to accurately describe problems in terms of their stakeholder impacts was one of the most useful skills she learned during her internship experience. 


\subsection{Social competence}

The area of social competence was discussed little by the participants, who found it difficult to differentiate this area from communication, organisational and team work skills. While several remarks were made on social competence, no theme that would meaningfully extend the main topic could be identified. Among the remarks, P3 stressed the importance of openness and mutual respect, especially in a diverse work environment. He also advised interns to learn how to build personal connections early, observing that personal networks contribute to long-term employability. P7 observed that success in social interactions can depend on small things like learning to address people appropriately and getting familiar with German food, improving conversations over lunches. On general level, P5 observed that trying to make it enjoyable for colleagues to work with her could gain her their support when she needed it.

\subsection{Initiative and proactive behaviour}

This area includes learning to come up with new ideas, present and defend them and turn them into action, as well as to behave proactively. It is therefore related to the concept of autonomy (subsection 3.2), which refers rather to the capability to work independently than start new action. Among the limited responses concerning this area, two themes were identified.

The first theme, benefiting of initiative, was brought up by P3 and P7, who believed their employers to value initiative in candidates for jobs. As P3 stated, "key to the assessment of people is, how much initiative do they bring, how much are they willing to contribute above what is expected from them in their roles." P7 saw initiative as a form of willingness to grow and learn with the organisation, which could be learned in an internship. Furthermore, P5, P6 and P7 linked initiative and proactive behaviour to improved feeling of control of one's own work, in particular under changing circumstances and high workload.

P2, P5 and P7 identified doubt in their abilities as the main constraint to initiative. Thus, the second theme, overcoming doubt, refers to the learning process of developing the self-efficacy underlying initiative. However, the participants could not specify this process, which seemed to emerge from daily work experiences and interactions with colleagues. Nevertheless, these findings match Edwards' (2014 [5]) proposition that internships are beneficial to student self-efficacy.

\subsection{Team work}

The area of team work gained little attention by the participants, partly because the participants found the skill inseparable from other areas. However, two distinct themes could be identified. P4, P6 and P9 mentioned the importance of speaking the same language with the theme, referring to harmonising the terminology and meanings attached to concepts among the team. P5 and P6 had team leader experience and pointed to a special competence of bringing projects to a close, comprising a balance of motivation, social and communication skills and task management skills. As P5 explained her success leading a team, "I can communicate with others ... properly and I can tell them what I expect of them clearly, and I can answer their questions. I get results from them [because of that], not because I'm particularly good in industrial engineering."

\subsection{Communication}

Because of the prevalence of communication in everyday work, the importance of communicating well and the impact of cultural differences on communication, several participants provided input to this area. The responses could be grouped around two broad themes.

All participants discussed their experiences of adapting to German communication style. In general, they saw major differences in communication between Germany and their native countries. P1, P2, P3, P4, P6 and P8 all pointed at similar learning experiences that resulted from both experience and instruction by supervisors. The participants observed their communication to become more successful as they learned to be more "facts focused", "direct and straightforward", "clear", "precise and to the point" and "effective". P6 observed that "people are very focused on their work, they can be nice to you but it's always professional and quite impersonal and you need to learn to respect that." P4 and P8 learned structure and preparation in communication, observing that meeting colleagues with a prepared agenda was received better than asking for repeated interaction. P2, P3 and P8 linked communication to the theme "knowing the organisation" (3.3), suggesting that successful communication often depended on pointing out a mutual benefit greater than the distraction 
caused. Most participants could use English as their work language but recognised its limitations and the importance of learning German for further career in Germany. P7, an intermediate-level German speaker, shifted his working language from English to German during his internship, which enhanced his integration to the workplace community.

As mentioned in subsection 3.1, at least five participants, interning at multinational corporations, had a distinctly international internship experiences. This allowed them to learn intercultural communication skills, captured in the theme bridging between cultures. P2, who interned at a headquarter organisation, observed that tasks, guidelines, objectives and concepts were interpreted differently in the company's organisations across the world, making "translating between cultures" a crucial work coordination competence. P5 and P6 saw mindful observation of others combined with study of cultures as key to learning intercultural communication. In practice, they perceived mutual understanding of culturally determined behaviour to add to work efficiency and decrease frustration especially in complex interactions.

\subsection{Learning to learn}

Explicit questions about learning to learn produced a number of general remarks only. The participants mentioned the importance of setting learning goals (P5), self-reflection supported by supervisor feedback (P7) and using online media for independent learning (P9). P6 remarked that because learning in the internship took many diverse forms, it was difficult to answer the question explicitly. P5 agreed, stating that a because learning happened through observation, doing, discussing, reading, participating seminars and workshops, taking online courses and possibly other media, a clear breakdown would be needed to analyse learning skills. However, among the whole data set, two themes underlying successful learning could be identified.

The first theme, developing will to learn, underlines the importance of attitude and motivation to learn. P4 thought his learning motivation was a key employability factor and told about his attitude that "as long as you want to learn, you will find a way." P7 asserted that "a learning mindset is the real transferable skill", observing that his performance at work and self-efficacy depended on his ability to learn. P3, who reported a socially active internship experience in a project management office, sought to "satisfy his curiosity by seeking opportunities to get involved in various colleagues' work." Though adding to his workload, he reported that doing so would earn him knowledge, connections and further career chances (the company hired him after graduation).

The second theme, driving learning through challenge, is related to the process of becoming autonomous (see subsection 3.2) and emerged from interviews with P2, P4, P5, P7 and P8. P2 noticed that with increasing workload and deadline pressure, he spent more time self-reflecting and matching his learning with the work priorities ahead. P5 held learning through responsibility central to internship learning and proposed it should belong to the employer's responsibilities to provide conditions that challenge the intern to learn.

Finally, when asked about learning while completing the self-assessment questionnaire, five participants (P2, P5, P6, P8 and P9) reported a positive experience, which P2 and P8 discussed further. The self-assessment had helped P2 to reflect on skills he "felt were very common" but had never assessed categorically; completing the questionnaire had helped him to "deep-dive" into the skills and evaluate his learning. In the same vein, P8 reported that the self-assessment "made [him] think a lot about [his] experience at [company] for the past one year." Benefiting from the selfassessment, he continued he was "really glad to have taken part in the study."

\section{CONCLUSION AND LIMITATIONS}

This paper investigated foreign students' perceptions of learning and deploying employability skills through internships at German companies. The investigation resulted in the development of 18 themes, representing attributes and processes of learning identified among the participants' reported experiences. The set of themes can be used as resource by academic staff advising foreign internship candidates or interns, as well as by students engaged in internship planning, goal-setting and conduct. The resource may help these stakeholders enhance the internship learning outcomes. Crucially, the set of themes may also allow internship providers to design better internship placements, improving the internship experience and benefits to all stakeholders.

The study conducted a thematic analysis, developing the themes on the basis of the data. Taking a further step to situate and discuss the themes within existing literature may reveal further insight on 
learning employability skills through internships. Further research and application opportunities include investigating individual themes in greater depth and developing and testing practices derived from the findings.

The study drew upon a small sample of nine participants, seven of whom studied in a single degree programme. In addition, the study was limited to foreign students' own perceptions of their learning. Therefore, the findings are considered provisional, illustrative and exploratory but not exhaustive.

\section{REFERENCES}

[1] J. Gault, E. Leach and M. Duey, "Effects of business internships on job marketability: the employers' perspective", Education + Training, Vol. 52, No. 1, pp. 76-88, 2010.

[2] J. Gault, J. Redington and T. Schlager, "Undergraduate Business Internships and Career Success: Are They Related?", Journal of Marketing Education, Vol. 22, No. 1, pp. 45-53, 2000.

[3] C.P. Maertz Jr, P.A. Stoeberl and J. Marks, "Building successful internships: lessons from the research for interns, schools, and employers", Career Development International, Vol. 19, No. 1, pp. 123-142, 2014.

[4] T. Wilson, "A Review of Business-University Collaboration", UK Department for Business, Innovation and Skills, 2012.

[5] M. Edwards, "The impact of placements on students' self-efficacy", Higher Education, Skills and Work-based Learning, Vol. 4, No. 3, pp. 228-241, 2014.

[6] R. Maelah, Z.M. Mohamed, R. Ramli and A. Aman, "Internship for accounting undergraduates: comparative insights from stakeholders", Education + Training, Vol. 56, No. 6, pp. 482-502, 2014.

[7] IHK Berlin, "Praktika in Unternehmen. Praxistipps für eine erfolgreiche Organisation und Durchführung.", Industrie- und Handelskammer zu Berlin, Berlin, 2011.

[8] F. Tompenaars and C. Hampden-Turner, "Riding the Waves of Culture: Understanding Diversity in Global Business", Nicholas Brealey Publishing, 1993.

[9] Federal Statistical Office (Germany), "Bildung und Kultur. Studierende an Hochschulen, Wintersemester 2014/15“, Fachserie 11, Reihe 4.1, 2015.

[10] Stifterverband and McKinsey, „Hochschulbildungsreport 2020, Jahresbericht 2015, Schwerpunkt: Internationale Bildung“, Stifterverband für die Deutsche Wissenschaft together with McKinsey \& Company, 2015.

[11] E. Hanganu and B. Hess, „Beschäftigung ausländischer Absolventen deutscher Hochschulen. Ergebnisse der BAMF-Absolventenstudie 2013.“, Federal Office for Migration and Refugees (Germany), Nuremberg, 2015.

[12] B. Sykes, „Mobile Talente? Ein Vergleich der Bleibeabsichten internationaler Studierender in fünf Staaten der Europäischen Union.", Sachverständigenrat deutscher Stiftungen für Integration und Migration, Berlin, 2012.

[13] P. Brown, A. Hesketh and S. Williams, "Employability in a Knowledge-driven Economy.", Journal of Education and Work, Vol. 16, No. 2, 2003.

[14] R. McQuaid and C. Lindsay, "The concept of employability", Urban Studies, Vol. 42, No. 2, 197219, 2005

[15] M. Fugate, A. Kinicki and B. Ashforth, "Employability: A psycho-social construct, its dimensions, and applications.", Journal of Vocational Behavior, 65, pp. 14-38, 2004.

[16] L. Dacre Pool and P. Sewell, "The key to employability: developing a practical model of graduate employability.", Education + Training, Vol. 49, No. 4, pp. 277-289, 2007.

[17] P. Knight and M. Yorke, "Assessment, Learning and Employability." Open University Press, 2003.

[18] M. Humburg, R. van der Velden and A. Verhagen, „The Employability of Higher Education Graduates: The Employers' Perspective", EU Research Centre for Education and the Labour Market, 2013. 
[19] J. Andrews and H. Higson, "Graduate Employability, 'Soft Skills' Versus 'Hard' Business Knowledge: A European Study", Higher Education in Europe, Vol. 33, No. 4, 2008.

[20] A. Green, M. de Hoyos, S.-A. Barnes, D. Owen, B. Baldauf and H. Behle, "Literature Review on Employability, Inclusion and ICT, Report 1: The Concept of Employability with a Specific Focus on Young People, Older Workers and Migrants.", EU Joint Research Centre, Luxembourg, 2013.

[21] V. Braun and V. Clarke, "Using thematic analysis in psychology.", Qualitative Research in Psychology, 3 (2), pp. 77-101, 2006. 